\title{
Contextual Fear Extinction and Re-Extinction in Carioca High- and Low-Conditioned Freezing Rats
}

\author{
Vitor de Castro Gomes ${ }^{1}$, Laura Andrea León², Daniel Mograbi1,3, Fernando Cardenas4, \\ Jesus Landeira-Fernandez ${ }^{1}$ \\ ${ }^{1}$ Pontifícia Universidade Católica do Rio de Janeiro, Rio de Janeiro, Brasil \\ ${ }^{2}$ Universidade de São Paulo, Ribeirão Preto, Brasil \\ ${ }^{3}$ Institute of Psychiatry, Kings College, London, UK \\ ${ }^{4}$ Universidad de los Andes, Bogotá, Colômbia \\ Email: landeira@psi.puc-rio.br
}

Received 4 May 2014; revised 4 June 2014; accepted 9 June 2014

Copyright @ 2014 by authors and Scientific Research Publishing Inc.

This work is licensed under the Creative Commons Attribution International License (CC BY).

http://creativecommons.org/licenses/by/4.0/

c) (i) Open Access

\begin{abstract}
We recently reported two novel breeding lines of rats known as Carioca High- and Low-conditioned Freezing (CHF and CLF), based on defensive freezing responses to contextual cues previously associated with electric footshock. The present study used animals of the $8^{\text {th }}$ generation of our selective breeding program to investigate both contextual fear extinction and re-extinction. The results consistently showed that CHF animals froze more than CLF animals. Long extinction training was able to extinguish phenotypic differences between lines, but the divergence was restored after just one fear reacquisition training session. These differences disappeared again during re-extinction training. The possible neural mechanisms involved in these two types of learning are discussed.
\end{abstract}

\section{Keywords}

Genetic Selection, Freezing Response, Fear Extinction

\section{Introduction}

Contextual fear conditioning represents one of the simplest animal models to investigate anxiety disorders. It involves placing an animal (e.g., a rat) in a novel environment and presenting an aversive unconditioned stimulus (US), such as a footshock. Defensive freezing behavior is one of the most reliable measures of contextual 
fear conditioning [1] because it is a direct function of shock intensity [2] and depends on the association between the cues of the experimental chamber and footshock [3]. The extinction of contextual fear conditioning consists of exposing the animal to contextual cues previously associated with footshock in the absence of the aversive US, thus leading to a decrease in the expression of defensive freezing behavior. Fear extinction does not appear to destroy the memory of conditioning but produces a new memory of conditioning [4]. This is clinically important because it resembles many features of behavioral treatment for many anxiety disorders [5].

Fear extinction has been shown to be mediated by specific neuronal circuits that are integrated in well-defined neural circuitry, including the amygdala, medial prefrontal cortex, and hippocampus [6]-[11]. Moreover, fear extinction requires many of the same cellular processes as memory reconsolidation, such as protein synthesis (protein kinase A and mitogen-activated protein kinase) and the activation of N-methyl-D-aspartate (NMDA) and $\beta$-adrenergic receptors [8]-[12]. Interestingly, recent findings indicated that a second extinction procedure after fear reacquisition, defined as re-extinction, is not mediated by the same cellular processes as fear extinction [13]. NMDA receptor activation is critically involved in fear extinction, whereas re-extinction learning appears to involve a transition to NMDA-independent circuitry [14] [15].

Selective breeding has been used to develop bidirectional lines of animals with high and low levels of defensive reactions, which in turn allows investigation of the pathophysiological mechanisms of anxiety disorders and the design of effective therapies. Our laboratory developed two novel selective breeding lines of rats, termed Carioca High- and Low-conditioned Freezing (CHF and CLF) that were selectively bred for high and low levels of defensive freezing responses to contextual cues previously associated with footshock. Gomes and LandeiraFernandez [16] found reliable differences between these two lines after three generations, indicating a strong heritable component of this type of learning. Previous results indicated that these two lines of animals were validated behaviorally in other innate animal models of anxiety, such as the elevated plus maze, social interaction test, and defensive responses induced by electrical stimulation of the dorsal periaqueductal gray [17]-[20]. However, no study has yet investigated fear extinction among these animals. Therefore, the present study explored the extinction and re-extinction patterns of these two lines of animals in response to the same contextual cues were that were previously phenotyped.

\section{Methods}

\subsection{Subjects}

The present study used rats that were selectively bred for high (CHF) and low (CLF) contextual fear conditioning according to procedures described in our previous work [16]. In the present study, we used 15 male CHF rats and 15 male CLF rats (12 - 20 weeks old; weighing $350-450$ g) from the $8^{\text {th }}$ generation of selective breeding. The animals were bred and maintained in the colony room in the PUC-Rio Psychology Department under a controlled room temperature $\left(24^{\circ} \mathrm{C} \pm 1^{\circ} \mathrm{C}\right)$ and $12 \mathrm{~h} / 12 \mathrm{~h}$ light/dark cycle (lights on 7:00 AM-7:00 PM). All of the behavioral experiments were conducted during the light phase of the light/dark cycle. The animals were housed in groups of three to five, according to their respective lines, in polycarbonate cages $(18 \mathrm{~cm} \times 31 \mathrm{~cm} \times 38 \mathrm{~cm})$ with food and water available ad libitum. The animals were handled once daily for 5 days for 2 min each day before the fear conditioning experiments. The experimental procedures reported herein were reviewed and approved by the Committee for Animal Care and Use of PUC-Rio (protocol no.20/2009) and performed in accordance with the guidelines for experimental animal research established by the Brazilian Society of Neuroscience and Behavior (SBNeC) and National Institutes of Health Guide for the Care and Use of Laboratory Animals.

\subsection{Apparatus}

The experiment was conducted in four observational chambers $(25 \mathrm{~cm} \times 20 \mathrm{~cm} \times 20 \mathrm{~cm})$ each placed inside a sound-attenuating box. A video camera was mounted on the back of each observational chamber so that the animal's behavior could be observed on a monitor placed in an adjacent room. A ventilation fan attached to the box supplied $78 \mathrm{~dB}$ background noise (A scale). The floor of each observational chamber was composed of 15 stainless-steel rods (4 mm diameter) spaced $1.5 \mathrm{~cm}$ center-to-center, which were wired to a shock generator and scrambler (AVS, SCR04; São Paulo, Brazil). An interface with eight channels (Insight, RibeirãoPreto, Brazil) connected the shock generator to a computer, which allowed the experimenter to apply an electric footshock. A digital multimeter was used to calibrate the shock intensities before each experiment. An ammonium hydroxide solution (5\%) was used to clean the chamber before and after each test. 


\subsection{Procedure}

During the acquisition phase, each animal was placed in the observation chamber for 8 min. At the end of this period, three $0.6 \mathrm{~mA}$ unsignaled electric footshocks were delivered (1 s duration, $20 \mathrm{~s}$ intershock interval). The animals were then returned to their home cage 3 min after the last shock. The next day, the animals were replaced to the same chamber for an 8-min period with no footshock or other stimulation during this period for the phenotyping testing session. A time-sampling procedure was used to assess fear conditioning in response to contextual cues. Every 2 s, the animal was observed, and a well-trained observer recorded episodes of freezing, which were defined as the total absence of movement of the body or vibrissa, with the exception of movement required for respiration. The 15 CHF rats with the highest levels of freezing and 15 CLF rats with the lowest levels of freezing were then chosen as breeders to create generation $\mathrm{S}_{9}$ of our ongoing selective breeding program. Two months after this initial session of aversive conditioning (phenotyping), the rats underwent the first extinction training, which consisted of 12 extinction sessions (one 8-min session per day). Extinction training consisted of the same testing procedure as our phenotyping protocol (i.e., the animals were returned to the same box where they received the footshocks on the previous day but without any stimulation). After completing the $12^{\text {th }}$ 8-min extinction session, all of the animals were subjected to a single reacquisition training session that used the same acquisition procedure as the acquisition procedure. Twenty-four hours after this reacquisition session, the animals were subjected to a second set of 12 extinction trials (re-extinction phase; one 8-min session per day). A time-sampling procedure was used to evaluate fear conditioning in response to contextual cues. Defensive freezing behavior was recorded during all of the extinction and re-extinction sessions.

\subsection{Statistical Analysis}

The amount of defensive freezing behavior is expressed as mean \pm standard error of the mean (SEM). To reduce the number of comparisons and increase statistical power, the extinction and re-extinction sessions were pooled into time session blocks, with every three sessions collapsed into one session block. A three-way mixed-design analysis of variance (ANOVA) was then performed, with session block (four levels; time points 1, 2, 3, and 4) and type of training (two levels; extinction and re-extinction) as the within-subject factors and line (CHF and CLF) as the between-subjects factor. When necessary, pairwise post hoc comparisons were performed using Student's t-test. The level of statistical significance was $p<0.05$.

\section{Results}

As expected, CHF rats displayed more defensive freezing behavior ( mean $=60.0$; SEM $=6.83$ ) than CLF rats (mean $=22.6$; SEM = 4.06) during the phenotyping testing session. Student's t-test revealed significant differences between these two groups of animals ( $\left.\mathrm{t}_{28}=4.55 ; p<0.001\right)$. Figure 1 shows the mean $( \pm \mathrm{SEM})$ percentage of freezing in the CHF and CLF lines during extinction and re-extinction training. The three-way ANOVA did not reveal significant interactions between line, session block, and type of training $\left(F_{3,84}=0.95, p=0.418\right)$, line and type of training $\left(F_{1,28}=0.64, p=0.429\right)$, or session block and type of training $\left(F_{3,84}=0.22, p=0.885\right)$. A significant two-way interaction was found between session block and line $\left(F_{3,84}=5.50, p=0.002\right)$. Pairwise comparisons indicated that the differences between CHF and CLF rats were observed only in the first session block $(p<0.00)$, both during extinction and re-extinction, with no significant differences in the other session blocks ( $p=0.251, p=0.427, p=0.951$, respectively). The analysis revealed significant main effects of type of training $\left(F_{1,28}=23.06, p<0.001\right)$, with a higher frequency of freezing during re-extinction, and session block $\left(F_{3,84}=25.56, p<0.001\right)$, with a decreasing frequency of freezing across time (all $\left.p<0.01\right)$, with the exception of session block 3 vs session block 4 ( $\mathrm{p}=0.207)$. No significant main effect of line was observed $\left(F_{1,28}=1.16, p\right.$ $=0.290)$.

\section{Discussion}

Consistent with previous reports, we observed a reliable difference in the acquisition of conditioned freezing behavior between the CHF and CLF lines. This difference was preserved 2 months after the initial aversive training, indicating robust long-term memory formation in CHF animals. These results are consistent with a previous report that indicated that rats can recall a dangerous context even 1 year after the initial aversive training 


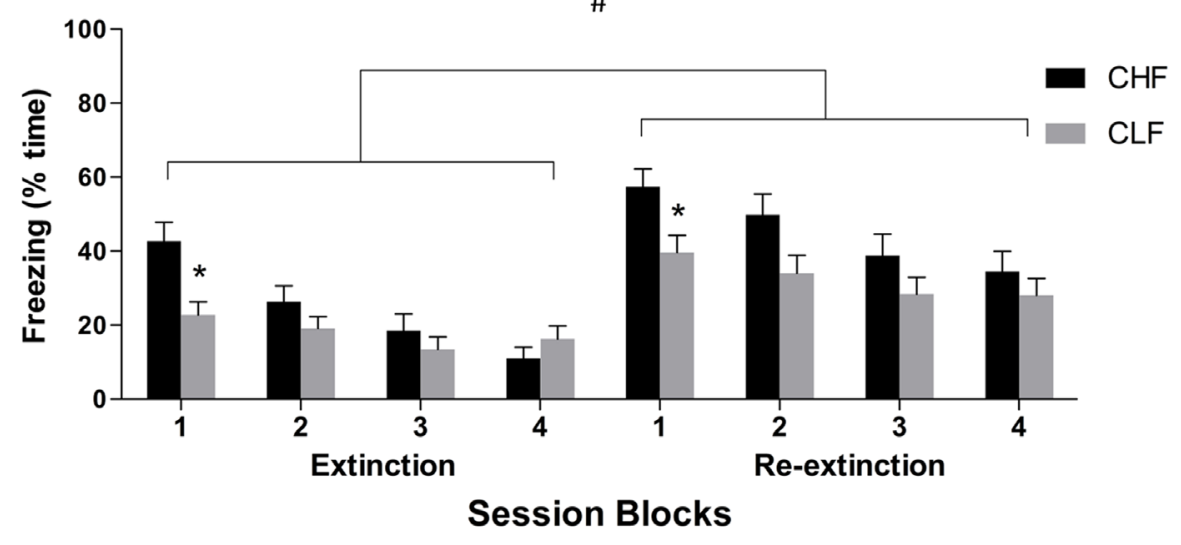

Figure 1. Mean percentage $( \pm S E M)$ of defensive freezing behavior in the CHF $(n=15)$ and CLF $(n=15)$ lines during extinction and re-extinction training. Sessions blocks are the average of three sessions. ${ }^{*} p<0.05$, significant difference between CHF and CLF in the first session block, both during extinction and re-extinction, with a higher amount of freezing among CHF animals. ${ }^{*} p<0.001$, significant difference between extinction and re-extinction training during the four session blocks, with a higher frequency of freezing during re-extinction training.

[21]. The basolateral amygdala (BLA) has been suggested to be particularly involved in the storage of life-time aversive memories in rats [22]. Recent studies from our group indicated that differential freezing behavior among the Carioca lines may arise from structures that are directly involved in fear conditioning, particularly the hippocampus [17]. Moreover, the dysfunction of biological protective systems, such as the redox system, are believed to be at least partially associated with different levels of fear conditioning acquisition and retrieval in the Carioca lines [20].

The main purpose of the present study was to evaluate the patterns of long extinction and reacquisition of contextual fear memories in rats selectively bred for high (CHF) and low (CLF) contextual conditioned freezing. The results indicated that long extinction training reduced the expression of defensive freezing behavior. More importantly, the initial differences observed between the CHF and CLF lines disappeared during extinction training. These results are consistent with the clinical exposure-based treatment of anxiety disorders [5] and suggest that our breeding lines represent a good animal model to investigate how different neural circuits are involved in fear extinction, thus facilitating the translation of behavioral neuroscience findings to clinical applications.

The present results also indicated that defensive freezing recovered after a single fear reacquisition procedure performed at the end of the $12^{\text {th }}$ extinction session. Freezing during the re-extinction sessions reached a higher plateau than during the first extinction training session. This observation corroborates previous findings, which showed that fear reacquisition results in stronger freezing compared with the initial aversive learning [23]. Moreover, the difference in the initial defensive freezing reaction between CHF and CLF animals recovered. Recent data suggest that the processes of fear acquisition and reacquisition are not driven by exactly the same cellular processes. Motanis and Maroun [24] reported that the initial formation of contextual fear memory depends on both protein synthesis and actin rearrangements in the BLA and hippocampal CA1 area. Actin rearrangements may facilitate the alterations in neuronal morphogenesis that underlie the cellular events involved in the formation of fear memories in the BLA and CA1 [25]. The reacquisition of contextual fear memory after re-exposure to CS-US presentations does not depend on new protein synthesis in the BLA but only on actin rearrangement in both the BLA and CA1 [24]. Altogether, these results suggest that the cellular processes for fear acquisition and reacquisition might be conserved in our selective breeding lines for high and low conditioned freezing acquisition and retrieval.

The extinction phase revealed that the differences in defensive freezing between CHF and CLF rats disappeared after re-extinction training. This finding is consistent with other reports that showed that re-extinction effectively reduces conditioned fear responses in rodents [13]. Moreover, other reports suggested that the BLA, which is crucial for fear extinction, is not directly recruited in re-extinction processes [15]-[23]. The cellular 
processes that regulate re-extinction are believed to be NMDA receptor-independent [14]. The alternative compensatory mechanisms that are involved in re-extinction are not fully understood, although findings indicate a primary role for the medial prefrontal cortex in this type of learning [26]. Although driven by processes distinct from fear extinction, re-extinction effectively mitigated the differences between the CHF and CLF lines. Further studies that utilize CHF and CLF lines with similar initial levels of freezing (e.g., after robust fear conditioning reacquisition) are necessary to fully investigate the genetic and neural differences in fear extinction and re-extinction patterns in the Carioca lines.

In summary, the present results showed that the continuous selective breeding process performed in our laboratory produced lines with robust phenotypic differences in conditioned freezing in response to contextual cues associated with footshock. The differences between the two lines were maintained 2 months after the initial fear conditioning, indicating strong formation of the long-term memory of contextual fear conditioning. Both rat lines reached the same asymptotic level of contextual fear extinction. Although the differences in freezing behavior between the CHF and CLF animals disappeared after 12 extinction sessions, the differences in freezing behavior reappeared after a single reacquisition session. These differences disappeared during the re-extinction phase. Selectively bred models of trait anxiety tested in fear extinction paradigms will continue to expand our knowledge about the genetic basis of anxiety disorders and their possible clinical treatments.

\section{Acknowledgements}

This research was supported by the Secretary for Science and Technology of Brazil (CNPq) and Fundação de Amparo à Pesquisa do Estado do Rio de Janeiro (FAPERJ).

\section{Author Disclosure Statement}

The authors have no financial conflicts of interest.

\section{References}

[1] Fanselow, M.S. (1984) What Is Conditioned Fear? Trends in Neurosciences, 7, 460-462. http://dx.doi.org/10.1016/S0166-2236(84)80253-2

[2] Sigmundi, R.A., Bouton, M.E. and Bolles, R.C. (1980) Conditioned Freezing in the Rat as a Function of Shock Intensity and CS Modality. Bulletin of the Psychonomic Society, 15, 254-256.

[3] Landeira-Fernandez, J. (1996) Context and Pavlovian Conditioning. Brazilian Journal of Medical and Biological Research, 29, 149-173.

[4] Maren, S. (2011) Seeking a Spotless Mind: Extinction, Deconsolidation, and Erasure of Fear Memory. Neuron, 70, 830-845.

[5] Vervliet, B., Craske, M.G. and Hermans, D. (2013) Fear Extinction and Relapse: State of the Art. Annual Review of Clinical Psychology, 9, 215-248. http://dx.doi.org/10.1146/annurev-clinpsy-050212-185542

[6] Herry, C., Ferraguti, F., Singewald, N., Letzkus, J.J., Ehrlich, I. and Lüthi, A. (2010) Neuronal Circuits of Fear Extinction. European Journal of Neuroscience, 31, 599-612. http://dx.doi.org/10.1111/j.1460-9568.2010.07101.x

[7] Ji, J. and Maren, S. (2007) Hippocampal Involvement in Contextual Modulation of Fear Extinction. Hippocampus, 17, 749-758.

[8] Knapska, E., et al. (2012) Functional Anatomy of Neural Circuits Regulating Fear and Extinction. Proceedings of the National Academy of Sciences of the United States of America, 109, 17093-17098. http://dx.doi.org/10.1073/pnas.1202087109

[9] Knapska, E. and Maren, S. (2009) Reciprocal Patterns of c-Fos Expression in the Medial Prefrontal Cortex and Amygdala After Extinction and Renewal of Conditioned Fear. Learning and Memory, 16, 486-493. http://dx.doi.org/10.1101/lm.1463909

[10] Quirk, G.J., Garcia, R. and González-Lima, F. (2006) Prefrontal Mechanisms in Extinction of Conditioned Fear. Biological Psychiatry, 60, 337-343. http://dx.doi.org/10.1016/j.biopsych.2006.03.010

[11] Monfills, M.H., Cowansage, K.K., Klann, E. and Ledoux, J.E. (2009) Extinction-Reconsolidation Boundaries: Key to Persistent Attenuation of Fear Memories. Science, 324, 951-955. http://dx.doi.org/10.1126/science.1167975

[12] Lattal, K.M., Radulovic, J. and Lukowiak, K. (2006) Extinction: [corrected] Does It or Doesn’t It? The Requirement of Altered Gene Activity and New Protein Synthesis. Biological Psychiatry, 60, 344-351.

http://dx.doi.org/10.1016/j.biopsych.2006.05.038 
[13] Langton, J.M. and Richardson, R. (2009) The Role of Context in the Re-Extinction of Learned Fear. Neurobiology of Learning and Memory, 92, 496-503. http://dx.doi.org/10.1016/j.nlm.2009.06.008

[14] Langton, J.M. and Richardson, R. (2008) D-Cycloserine Facilitates Extinction the First Time but Not the Second Time: an Examination of the Role of NMDA across the Course of Repeated Extinction Sessions. Neuropsychopharmacology, 33, 3096-3102. http://dx.doi.org/10.1038/npp.2008.32

[15] Laurent, V., Marchand, A.R. and Westbrook, R.F. (2008) The Basolateral Amygdala Is Necessary for Learning but Not Relearning Extinction of Context Conditioned Fear. Learning and Memory, 15, 304-314. http://dx.doi.org/10.1101/lm.928208

[16] Gomes, V.C. and Landeira-Fernandez, J. (2008). Amygdaloid Lesions Produced Similar Contextual Fear Conditioning Disruption in the Carioca High- and Low-Conditioned Freezing Rats. Brain Research, 1233, 137-145. http://dx.doi.org/10.1016/j.brainres.2008.07.044

[17] Dias, G.P., et al. (2014) Hippocampal Biomarkers of Fear Memory in an Animal Model of Generalized Anxiety Disorder. Behavioural Brain Research, 263, 34-45. http://dx.doi.org/10.1016/j.bbr.2014.01.012

[18] Galvão, B.O., Gomes, V.C., Maisonnette, S. and Landeira-Fernandez, J. (2011) Panic-Like Behaviors in Carioca Highand Low-Conditioned Freezing Rats. Psychology and Neuroscience, 4, 205-210. http://dx.doi.org/10.3922/j.psns.2011.2.005

[19] Gomes, V.C., Silva, C.E.B. and Landeira-Fernandez, J. (2011) The Carioca High- and Low-Conditioned Freezing Lines: A New Animal Model of Generalized Anxiety Disorder. In: Kalinin, V., Ed., Anxiety Disorders, InTech, Rijeka, 121-134. http://dx.doi.org/10.5772/23598

[20] Hassan, W., Gomes, V.C., Pinton, S., Batista Teixeira da Rocha, J. and Landeira-Fernandez, J. (2013) Association between Oxidative Stress and Contextual Fear Conditioning in Carioca High- and Low-Conditioned Freezing Rats. Brain Research, 28, 60-67. http://dx.doi.org/10.1016/j.brainres.2013.03.039

[21] Gale, G.D., et al. (2004) Role of the Basolateral Amygdala in the Storage of Fear Memories across the Adult Lifetime of Rats. Journal of Neuroscience, 24, 3810-3815. http://dx.doi.org/10.1523/JNEUROSCI.4100-03.2004

[22] Fanselow, M.S. and Gale, G.D. (2003) The Amygala, Fear, and Memory. Annals of the New York Academy of Sciences, 985, 125-134. http://dx.doi.org/10.1111/j.1749-6632.2003.tb07077.x

[23] Leung, H.T., Bailey, G.K., Laurent, V. and Westbrook, R.F. (2007) Rapid Reacquisition of Fear to a Completely Extinguished Context is Replaced by Transient Impairment with Additional Extinction Training. Journal of Experimental Psychology: Animal Learning and Cognition, 33, 299-313. http://dx.doi.org/10.1037/0097-7403.33.3.299

[24] Motanis, H. and Maroun, M. (2012) Differential Involvement of Protein Synthesis and Actin Rearrangement in the Reacquisition of Contextual Fear Conditioning. Hippocampus, 22, 494-500. http://dx.doi.org/10.1002/hipo.20915

[25] Bergstrom, H.C., McDonald, C.G., Dey, S., Tang, H., Selwyn, R.G. and Johnson, L.R. (2013) The Structure of Pavlovian Fear Conditioning in the Amygdala. Brain Structure and Function, 218, 1569-1589. http://dx.doi.org/10.1007/s00429-012-0478-2

[26] Chang, C.H. and Maren, S. (2011) Medial Prefrontal Cortex Activation Facilitates Re-Extinction of Fear in Rats. Learning and Memory, 18, 221-225. http://dx.doi.org/10.1101/lm.2070111 
Scientific Research Publishing (SCIRP) is one of the largest Open Access journal publishers. It is currently publishing more than 200 open access, online, peer-reviewed journals covering a wide range of academic disciplines. SCIRP serves the worldwide academic communities and contributes to the progress and application of science with its publication.

Other selected journals from SCIRP are listed as below. Submit your manuscript to us via either submit@scirp.org or Online Submission Portal.
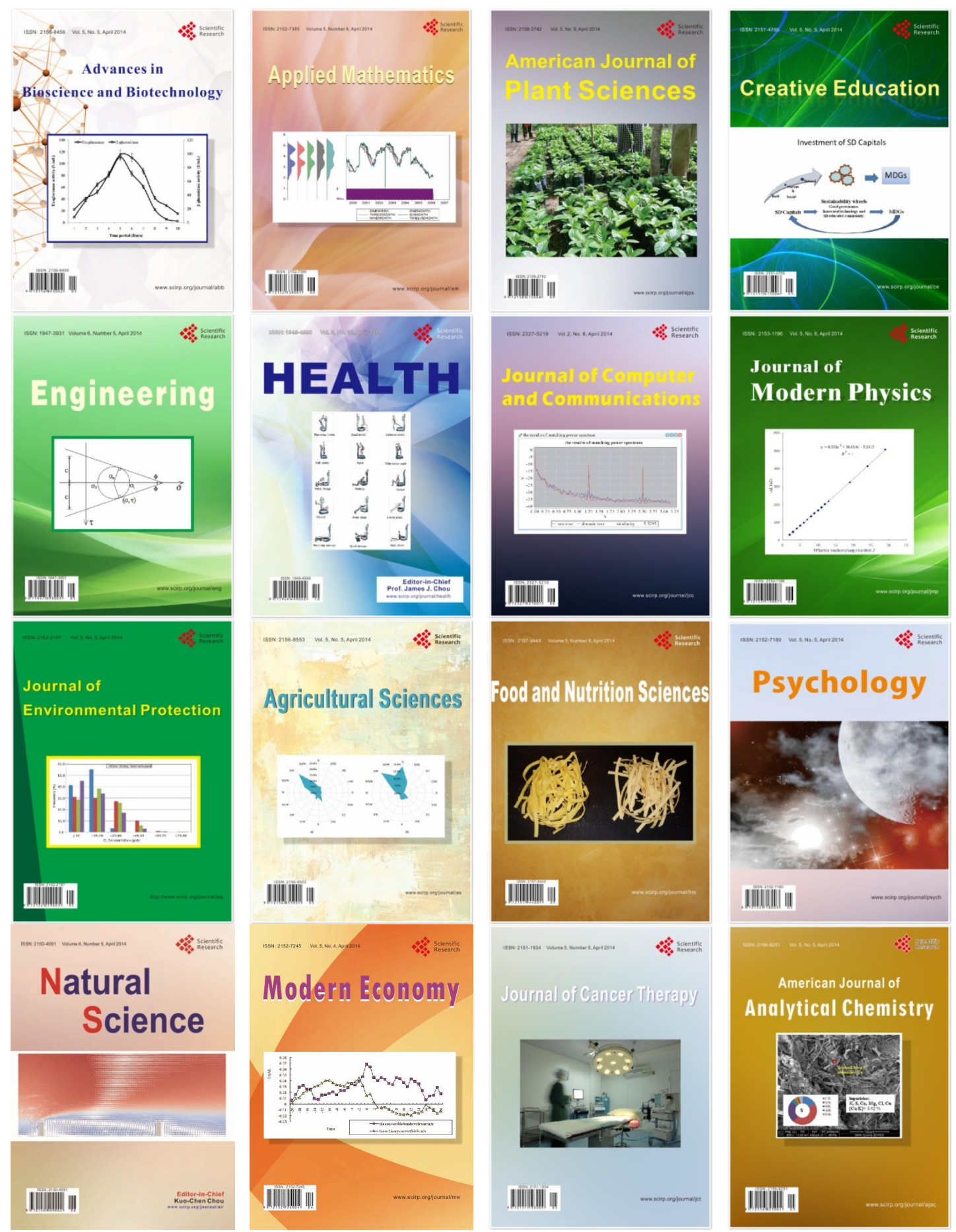